Published in Social and environmental accountability journal, 2017, vol. 37, no. 3, pp. 155-173, which should be cited to refer to this work.

\title{
EYE-TRACKING EXPERIMENTS IN SOCIAL AND ENVIRONMENTAL ACCOUNTING RESEARCH
}

\author{
Charles H. Cho
}

Schulich School of Business, York University, Toronto, Ontario, Canada;

\section{Amy M. Hageman}

Department of Accounting, Kansas State University, Manhattan, KS, USA

\section{Tiphaine Jérôme}

Ecole hôtelière de Lausanne, HES-SO // University of Applied Sciences

Western Switzerland, Lausanne, Switzerland

\begin{abstract}
In this article, we demonstrate the relevance of eye-tracking experiments in social and environmental accounting (SEA) research. Up to now, this type of design has been used in some areas within accounting research, but SEA has been neglected. If one is to adopt a user perspective [Merkl-Davies, D. M., and N. M. Brennan 2007. "Discretionary Disclosure Strategies in Corporate Narratives: Incremental Information or Impression Management?" Journal of Accounting Literature 27: 116-196; 2011. “A Conceptual Framework of Impression Management: New Insights from Psychology, Sociology and Critical Perspectives." Accounting and Business Research 41 (5): 415-437], the investigation and the understanding of the way social and environmental information affects user perceptions and decisions requires, among other tools, the use of eye-tracking setups. We discuss the need for eyetracking experiments in SEA research and provide some preliminary evidence on their usefulness by conducting an illustrative experiment.
\end{abstract}

Keywords: CSR perception; CSR report; eye-tracking experiment 


\section{EYE-TRACKING EXPERIMENTS IN SOCIAL AND ENVIRONMENTAL ACCOUNTING RESEARCH}

\section{Introduction}

While a number of experimental studies in the social and environmental accounting (SEA) area have been conducted, the vast majority of research in the field still uses either archival-type investigations (e.g., based on large sample quantitative data) or a qualitative methodology approach (e.g., based on interview data), and the use of experiments still remains rare. ${ }^{1}$ In a survey of research methods utilized in the extant SEA literature, Alewine (2010) identifies five monumental studies in the environmental accounting field - Kennedy, Mitchell, and Sefcik (1998), Milne and Patten (2002), Cho et al. (2009), Kaplan and Wisner (2009), and Chen, Arnold and Sutton (2010) but yet documents a substantial lack of experimental studies in the area. $^{2}$ Given such scarcity, he argues that there is a need for more experimental research in the SEA field and provides insights about how some of the unique methodological advantages of experiments can help address important social and environmental (S\&E) issues.

This lack of experimental studies in the SEA literature is somewhat of concern, especially given the types of conclusions that may be gleaned from using this methodology. According to Kerlinger and Lee (2000, 579), laboratory experiments have the distinct advantage of offering strong control, high internal validity, precision, and 'controlled [...] measurement in an environment from which possible "contaminating" conditions have been eliminated.' Thus, SEA researchers wishing to observe behavior in a tightly-controlled environment devoid of other potential confounding factors would be well-advised to use experiments as a design choice. Experiments are also invaluable for gathering individual

\footnotetext{
${ }^{1}$ According to Parker (2005), experimental studies represent only about $1 \%$ of the SEA literature.

${ }^{2}$ Since then, while some new experimental studies have been conducted (e.g., Alewine and Stone, 2016; Dilla et al., 2014; Elijido-Ten, 2011; Wynder et al., 2013), Alewine's (2010) analysis remains true - there are still very few experimental studies in the SEA literature.
} 
perceptions. In the SEA literature, the use of experiments can therefore be used to uncover individual perceptions and attitudes pertaining to S\&E reporting - information that is unavailable in large-scale archival data sets.

For example, archival research demonstrates that graph usage in annual reports may be used for impression management (e.g., Beattie and Jones, 2000a), particularly in certain countries (Beattie and Jones, 2000b). However, while archival research is able to show overall trends in the graphs used in annual reports (such as the relationship between graph choice and company performance), this type of methodology is unable to resolve how such choices and trends actually influence users' perceptions. Experimental studies are able to address these questions of user perceptions. In the example of graph usage, an experimental study has demonstrated that users are indeed likely to be misled by 'distorted graph's' (Beattie and Jones, 2002) - particularly those users with lower levels of financial knowledge. Thus, experiments are able to confirm or disconfirm findings from archival studies - as well as drill deeper about the processes behind individuals' perceptions.

Impression management and potentially distorted graphs are also found in S\&E reporting (Cho, Michelon, and Patten 2012a). However, most studies within the SEA literature use an archival methodology - which enables for the examination of large-scale patterns across a data set, but is silent about how users might actually react and interact with this information. In particular, understanding how $\mathrm{S} \& \mathrm{E}$ or corporate social responsibility (CSR) user reports actually interact with and react to text, graph, and pictorial disclosures is an important next step for determining how environmental reporting disclosures are actually perceived by stakeholders. Here again, using an experimental methodology is a useful tool for studying users' reactions to CSR disclosures - and, in particular, using a laboratory setting to examine how users actually interact with and perceive such disclosures enables for user behaviour to be studied without the inclusion of confounding factors. 
One type of experimental method that may be particularly fruitful for these types of SEA studies is an eye-tracking experiment - that is, a laboratory experiment conducted with eye-tracking technology ${ }^{3}$. Eye-tracking devices use sensors to track where an individual's eye is focused. Such eye-tracking technology is fairly unobtrusive - thus lending a high degree of internal validity and control in the experiment, as well as precision ${ }^{4}$ in the measurement of user behaviour. Using eye-tracking technology also has the advantage of being able to study users' actual behavior. In other words, instead of relying upon self-assessment of perceptions of a CSR report, eye-tracking technology enables the measure of actual visual attention.

In this methodological note, we seek to demonstrate the relevance of eye-tracking experiments in SEA research. As such, we first document the benefits of such experiments and provide insights on how they would shed light on important issues and research questions within the SEA area. We then present the results of an illustrative eye-tracking experiment in which we study the association between the visual attention spent on specific mediums within a standalone CSR report by users and (1) their trusting intentions/beliefs and (2) their perceptions of the company's CSR level.

We contribute to the SEA literature by providing insights and potential implications of eye-tracking experiments for future research, and investigating which specific elements contained within a standalone CSR report appear to have an impact on the level of trust and perception of CSR exhibited by users. In particular, we highlight that eye-tracking research offers a unique benefit over other methodologies by allowing researchers to ascertain precisely what portions of CSR reports are examined by users. We conclude with a discussion of the importance of eye-tracking experiments in future SEA research.

\footnotetext{
${ }^{3}$ See Appendix 1 for a summary of previous research on eye-tracking experiments.

${ }^{4}$ Eye-tracker devices currently sold in the market are becoming gradually reliable due to technological innovations (Wedel and Pieters, 2007).
} 


\section{Eye-Tracking Experiments in SEA Research}

In line with the arguments above, Wong and Millington $(2014,864)$ note that ' $[\ldots]$ relatively little is known about [...] the usefulness of corporate social disclosure to stakeholders [...]'. That is, questions about how stakeholders view and perceive S\&E information, their preferences and expectations, and the effects of such information on their decisions constitute areas that are relatively underexplored.

Merkl-Davies and Brennan $(2011,432)$ underline '[...] the difficulty of capturing the response of organisational audiences other than shareholders ${ }^{5}$ to impression management by conventional archival methods'. This goes back to the fact that while archival methods can provide correlations, they do not allow determine the actual influence power of such information (S\&E or other) on the perceptions and decisions made by stakeholders. As such, eye-tracking methods would help in assessing the reaction to S\&E disclosure of a variety of stakeholders through two steps. First, eye-tracking technology enables researchers to identify drivers of visual attention to $\mathrm{S} \& \mathrm{E}$ information disclosed in a variety of communication media (websites, corporate reports, press releases, etc.). First, eye-tracking technology enables researchers to identify drivers of visual attention to S\&E information disclosed in a variety of communication media (websites, corporate reports, press releases, etc.). Second, eye-tracking technology helps determine whether and to what extent visual attention plays a role in the reaction to S\&E information. Figure 1 summarizes the two steps.

\section{[Figure 1 about here]}

First, thanks to eye-tracking experiments, one can assess how both user types (e.g., financial analysts, consumers, individual users, institutional investors, shareholders, etc.) and user characteristics (e.g., attitudes towards CSR, degree of sophistication, information

\footnotetext{
${ }^{5}$ Studies on shareholders are primarily based on investment decisions and share price reactions.
} 
acquisition strategies, ${ }^{6}$ etc.) influence the degree of visual attention on S\&E information. Apart from filling ex-post questionnaires and interviews, ${ }^{7}$ it is very difficult to access this type of information (Wedel and Pieters, 2014) in a corporate reporting context, and collected data may suffer from bias as users may say one thing and actually do another one. ${ }^{8}$ Eye-tracking designs could usefully supplement existing studies on CSR information needs of certain categories of users. For instance, in a recent study, using survey responses, Cohen, Holder-Webb, and Zamora (2015) document, among other aspects, variations in demands of professional and nonprofessional investors for different categories of non-financial information including CSR. In particular, they show that for the subgroups whose investment research consists of at least a quarter of socially responsible investments (SRI), the demand for CSR information is higher when the SRI investor level is lower. An eye-tracking experiment could complete this study by measuring the actual time spent looking at CSR information by low SRI investors, compared to high SRI ones, to help determine whether the attitude towards CSR information reported in the (rationalised) survey responses is associated with the actual behaviour of both types of investors.

Furthermore, eye-tracking experiments may be useful to assess both the individual and the joint influence of information content and presentation on visual attention directed to S\&E information. Indeed, as Merkl-Davies and Brennan $(2011,431)$ state, 'relatively little is known about the influence of the content and presentation of corporate narrative documents on organisational audiences.' Again, eye-tracking setups may be used to supplement existing studies (e.g. Cho et al., 2009) to determine whether and how visual attention differs across

\footnotetext{
${ }^{6}$ Merkl-Davies and Brennan $(2011,431)$ note that 'there is little evidence on the information acquisition strategies undertaken by different strata of that audience'.

${ }^{7}$ Researchers also use mouse clicks in the domain of internet search to proxy for users' attention for example but they provide much less detailed data than eye-tracking (Cutrell and Guan, 2008).

${ }^{8}$ For example, Reimsbach and Hahn (2015) report, for a subgroup of experiment participants, an inconsistency between actual and perceived behavior. They ask participants to report whether the CSR information they read affected their judgments of stock price. $27.3 \%$ of the sample indicated that the additional sustainability information had no effect on their estimates while only $16.8 \%$ did not revise their initial assessments.
} 
S\&E information dimensions such as quantitative versus qualitative, future-oriented versus past-oriented, high-quality versus low-quality, environmental versus social, pictures versus texts, etc.

The two dimensions depicted in the drivers' boxes (users and information) can also interact (see the dashed arrows). For example, among the user characteristics, cognitive styles are important to consider. Cognitive styles are 'consistent individual differences in preferred ways of organising and processing information and experience' (Messick, 1976, 5). Eyetracking experiments may be useful for two purposes in this regard. First, these experiments could provide evidence on cognitive styles and thus confirm the first evaluation done with tests (Nisiforou, Michailidou, and Laghos., 2014). Second, eye-tracking experiments could also highlight differences in the attentional processes related to cognitive styles. Indeed, several studies show that elements to which people pay attention differ depending on their cognitive style (Braun et al., 2009; Tsianos et al., 2009; Mawad et al., 2015). According to Merkl-Davies and Brennan (2007), users' cognitive style could influence differences in users' receptiveness to impression management. $\mathrm{S} \& \mathrm{E}$ information raises the same question how does users' cognitive style influence visual attention on S\&E information and, then, users' perceptions? Also, do all stakeholders have the same preferences on S\&E information and how do these preferences influence their use of such information?

Second, once visual attention has been measured and its drivers are known, it can be used as an independent variable to fill a gap in current SEA knowledge - does (and to what extent) visual attention to $\mathrm{S} \& \mathrm{E}$ information affect decisions and perceptions? What are the implications of being exposed to S\&E information on decisions making? Previous SEA studies rely primarily on decision outcomes without knowing how decisions have been driven by the precise items the users looked at (see Alewine, 2010). Reactions and decisions investigated 
may be related but are not limited to management accounting, financial accounting, investment, or other.

Overall, we believe eye-tracking experiments will be useful to understanding both the determinants of visual attention on S\&E information and its potential influence, which will help enrich the findings from existing studies. For example, seminal archival studies such as Murray et al. (2006) could be revisited and deepened. They show that high (low) returns are associated with high (low) levels of S\&E information. The disclosure variables are computed from the number of pages dedicated to S\&E issues in an annual report. In addition to the volume of information, one could also investigate which content is considered and determine which specific elements ${ }^{9}$ have an influence on returns. Recent experimental studies could also benefit from the eye-tracking technology. For example, Zahller, Arnold and Roberts (2015) show that higher quality CSR information increases perceived organisational legitimacy, which, in turn, generates a greater level of organisational resilience to an exogenous shock - what role does visual attention play in this process and which qualitative informational items matter most? Reimsbach and Hahn (2015) demonstrate that disclosure of negative incidents by a nongovernmental organization (NGO) has a negative effect on stock price assessments and investment decisions compared with judgments based on financial information only. This effect exists only when the firm does not simultaneously report these bad news. To reach these conclusions, the authors created a sustainability report from an actual one and an independent industry report disclosed by a fictitious NGO. They inserted a list of negative incidents (and corrective actions undertaken) in three fields (underage labor, weekly working hours, and discriminatory practices). In the online supplemental material, one can see that the information is presented using different font sizes, colors, etc. First, relying on an eye-tracking device would

\footnotetext{
${ }^{9}$ Some studies analyze the influence of specific S\&E information release such as greenhouse gases (Matsumara et al., 2015) but information is extracted from other channels than corporate reports (Carbon Disclosure Project in this example) and is isolated from other S\&E information areas.
} 
allow to easily and rapidly ${ }^{10}$ identify which of the three areas (if any) attracted most attention of the readers and whether this is associated with their stock price assessments. Second, and this is only possible with an eye-tracker, one could also assess which portions of text are most considered and how this influence the share price and investment decisions.

Insufficiently explored S\&A issues will also benefit from the introduction of eyetracking experiments. In a review of CSR research in accounting, Huang and Watson (2015) note that there is almost no evidence regarding cost of actions that are not consistent with the firm's socially responsible image. One potential explanation for this phenomenon is the existence of a confirmation bias. ${ }^{11}$ They encourage researchers to carefully investigate and document the existence and the extent of a confirmation bias in the CSR context, which likely requires the use of an eye-tracking setup.

To further demonstrate the usefulness of eye-tracking experiments in SEA research, we conduct an illustrative experiment that examines visual attention among users in a CSR report. This illustrative experiment is conducted both to assess actual visual attention among different parts/components of the report, as well as to assess how such visual attention is related to user attitudes and beliefs. This eye-tracking experiment potentially adds to our extant knowledge regarding SEA research by investigating the actual portions of a CSR report that users focus on.

\section{Illustrative Experiment}

\subsection{Background}

We rely on computerised eye-movement retinal imaging technology in order to capture the eye-movement patterns and strategy of report users. The eye-tracker device used is an improved version of the pupil center infrared corneal reflection technique. Our illustrative

\footnotetext{
${ }^{10}$ This is compared to running an additional experiment to distinguish between the three areas.

${ }^{11}$ Confirmation (or confirmatory) bias is the tendency to seek out information in a way that reinforces one's preexisting hypotheses and ignore information that is not in accordance with prior beliefs.
} 
experiment aims at identifying which information types (i.e., text, charts, images) of nonfinancial information contained in a given standalone CSR report are considered with more attention by report users and how it affects user trusting intentions and beliefs, and perceptions of company's S\&E responsibility.

\subsection{Trust}

We adapt the trust model of McKnight, Choudhury, and Kacmar (2002), who focus on the types of trust exhibited by consumers towards organisations in the context of reports and other information provided by the organisation. Specifically, the trust model of McKnight Choudhury and Kacmar (2002) distinguishes between trusting beliefs ${ }^{12}$ and trusting intentions ${ }^{13}$ that an individual may hold for an organisation. While trusting beliefs are an individual's beliefs that someone else has favourable qualities, trusting intentions represent an individual's willingness to depend upon another party.

\subsection{CSR Reports and Legitimacy}

A CSR report is a voluntary report produced by an organization disclosing information about a company's environmental and/or community activities. This type of reports is generally used as a channel and vehicle for S\&E information, which can help companies achieve legitimacy. ${ }^{14}$ However, the construct of legitimacy is by definition rooted in individuals' perceptions. While most prior studies of CSR reports are archival in nature, both Milne and Patten (2002) and Cho et al. (2009) experimentally examine factors that influence perceptions of corporate S\&E responsibility. Milne and Patten (2002) establish that the content of CSR reports can influence these perceptions, while Cho et al. (2009) show that the medium used for

\footnotetext{
${ }^{12}$ Trusting beliefs, in McKnight et al.'s (2002) e-commerce framework, are perceptions of favorable website attributes, including 'competence', 'benevolence', and 'integrity' (McKnight et al., 1998).

${ }^{13}$ Trusting intentions are more closely related to the intention to engage in trust-related behaviors; that is, greater trusting intentions increase the likelihood that an individual will depend upon the other party (McKnight et al., 2002).

${ }^{14} \mathrm{~A}$ vast stream of literature on legitimacy theory has proposed that these environmental and social disclosures are often centered on organizations' concerns regarding their legitimacy. Legitimacy theory is rooted in the idea of the social contract, or that a company's continued existence is predicated on being perceived as operating in a 'legitimate' or socially acceptable manner, by the rest of society (Deegan et al., 2002).
} 
disclosure can also affect these perceptions. Thus, one important output of individuals' interactions with CSR reports concerns their perceptions of corporate S\&E responsibility. In order for individuals to rely upon CSR reports, however, they must have a sufficient level of trust with the organisation and the information presented.

\subsection{Development of Research Questions}

Building on prior research and legitimacy theory, we develop several exploratory research questions that utilise eye-tracking technology to investigate how CSR information is used. Under their experimental setup with an investment scenario, Milne and Patten (2002) found that under some circumstances, environmental disclosures could potentially mislead users regarding their perceptions of corporate legitimacy. In another experimental study, Cho et al. (2009) documented that CSR disclosures presented in richer media were more likely to engender a higher level of trusting intentions and a higher level of user perception of corporate S\&E responsibility. Thus, both of these studies experimentally examine factors that influence trusting beliefs/intentions as well as perceptions of CSR.

What has not yet been investigated, however, relates to any potential association(s) between the visual attention and time spent by users on specific types of information (i.e., text, charts or images) within a CSR report and (1) their trusting intentions and beliefs and (2) their perceptions of the company's S\&E responsibility. Given the importance of understanding these constructs, and the exploratory nature of the investigation, we formally ask our research questions that will be explored via eye-tracking technology as follows:

$\mathrm{RQ}_{1}$ : What type(s) of S\&E information is (are) associated with user trusting intentions and beliefs?

$\mathrm{RQ}_{2}$ : What type(s) of S\&E information is (are) associated with user perceptions of corporate $S \& E$ responsibility?

\subsection{Research Method}

Potential participants to the eye-tracking experiment were contacted by e-mail and other 
social networks in a French business school. Participation in the experiment was incentivised by a small gift card at a large retail store. The final pool used for analysis consisted of 102 participants. The demographic information about the final sample participants is presented in Table 1.

\section{[Table 1 about here]}

The experimental task consisted of the evaluation of a CSR report of 'CTA Enterprises'. In order to create the most realistic environment for viewing a standalone CSR report and allowing individuals to complete the experiment on their own time in a naturalistic setting, the CSR report was taken directly from a real-world one published by a US company. However, the researchers changed the company name in the report to a fictional one-

CTA Enterprises - to avoid any potential bias toward the actual company (Zhilong, Rui and Wen 2011). This report had 14 pages, including charts, images, and texts covering various CSR themes.

The experiment took place in a room specifically dedicated to the experiment on the French business school campus. When participants arrived, they first had to read and sign an informed consent form. ${ }^{15}$ The experimental task consisted of browsing and reading the 14-page standalone CSR report, which was displayed on the screen, and then answering an online questionnaire. Participants were instructed to act naturally as if they were given a standalone CSR report.

Similar to Atalay, Bodur, and Rasolofoarison (2012), the participants were placed in front of a Tobii 1750 video-based eye-tracking machine. ${ }^{16}$ The screen of this particular machine is 17 inches wide with a resolution of 1280 by 1024 pixels and a frequency of 50 hertz (i.e., the screen is refreshed 50 times per second). Before any viewing and recording occurs,

\footnotetext{
${ }^{15}$ Institutional Review Board (IRB) approval was obtained from one of the authors' institution prior running the experiment.

${ }^{16}$ Given that we used the same eye-tracking machine as Atalay et al. (2012), we provide here a slightly condensed version of the machine specificities.
} 
the eye-tracker is individually calibrated for each participant. As participants view the CSR report on the screen, an infrared camera located below the screen inconspicuously records participants' eye movements and tracks at which location on the screen their eyes fixated at any time. Figure 2 displays a sample eye gaze map output of a sample participant's eye gaze pattern while viewing one of the pages of the CSR report.

\section{[Figure 2 about here]}

After reviewing the CSR report, participants responded to an online questionnaire measuring attitudes and demographic information. Table 2 presents a summary of participant attitudes, indicating that the majority of participants cared about S\&E performance, considered this performance when making decisions, and had some existing familiarity with a CSR report. ${ }^{17}$

\section{[Table 2 about here]}

Following Cho et al. (2009), three primary dependent variables were of interest in this study: (1) trusting intentions, (2) trusting beliefs, and (3) perceptions of the company's S\&E responsibility. The variable measuring the latter variable - S\&E responsibility ( $S \& E$ Responsibility) - was measured on a 7-point scale with higher values indicating higher levels of perceived S\&E responsibility. The average response to the S\&E Responsibility was 6.04 (out of 7), indicating that most participants felt that the company was fairly socially and environmentally responsible.

The items for the variables measuring Trusting Intentions and Trusting Beliefs originated from McKnight, Choudhurry, and Kacmar (2002). ${ }^{18}$ Trusting Beliefs had an average

\footnotetext{
17 This experiment was pilot tested with six graduate students under normal experimental conditions. Based on the feedback from these pilot tests, several changes were made to the wording of items on the questionnaire and to the resolution of the CSR report text.

${ }^{18}$ Trusting intentions signified participants' willingness to rely upon information in the CSR report, whereas trusting beliefs signified participants' integrity trusting belief in the company. Following McKnight et al. (2002), nine questions assessing these trust dimensions, each on a 7-point scale, were included on the questionnaire (see Appendix 1). Factor analysis indicated that following McKnight et al. (2002) and Cho et al. (2009), four of these questions loaded onto the Trusting Beliefs variable, whereas five questions loaded onto the Trusting Intentions variable. The dependent variable measures for this study used the summed response to these measures.
} 
summed score of 20.51 (out of 28 possible points), whereas Trusting Intentions had an average summed score of 23.23 (out of 35 possible points). Reliability analysis further indicated that these measures were both valid scales (Cronbach's alpha of 0.869 for Trusting Beliefs and 0.790 for Trusting Intentions).

Our primary independent variable is the total time spent viewing the CSR report. We measure this variable with both the total time spent viewing the report in total and the time spent viewing the various mediums within the report (images, charts, and text).

We measure 'time' in two ways: (1) the count of the total number of fixations within the report which exceed 100 milliseconds, and (2) the total length of time spent viewing the report (only including the gazes that exceeded 100 milliseconds). ${ }^{19}$ Due to the high correlation between the 'count' of eye gazes and the 'time' spent on eye gazes, our analyses use total length of time as the primary variable.

\subsection{Results}

In our analysis, we assess whether the total time participants spent viewing the report is associated with any of our dependent variables. Table 3, Panel A presents the results of regressing each of our three dependent variables (S\&E Responsibility, Trusting Beliefs, and Trusting Intentions) on total time. We find that the longer participants examined the CSR report, the higher and more favourable they viewed the company's level of S\&E responsibility; however, this was not related to their trusting beliefs or trusting intentions associated with the company. This is in contrast to the findings of Cho et al. (2009); however, eye-tracking technology enables the investigation of time spent on specific information, and thus provides a finer-grained perspective than earlier experimental studies for examining this issue.

\section{[Table 3 about here]}

\footnotetext{
${ }^{19}$ We follow Atalay et al. (2012) and use 100 milliseconds as the cut-off, since fixations below this threshold are unlikely to add any information acquisition.
} 
Table 3, Panel B presents the results of the analysis of the effect of the duration of eye gazes for the three different types of medium in the report (text, charts, and images) to determine if greater exposure to one of these medium types is associated with greater trust or perceptions of S\&E responsibility. We find that our previous finding that greater time spent viewing the CSR report was associated with stronger perceptions of S\&E responsibility appears to be driven by the time participants spent viewing the text of the report. In particular, participants perceived the company as having higher levels of S\&E responsibility if they spent longer viewing the text of the report, and had higher levels of trusting intentions as well. The time spent on images did not matter. Interestingly, participants had lower levels of trusting intentions if they spent more time viewing charts. Perhaps the lack of trust related to charts could be related to companies' use of impression management and legitimating strategies with graphs in CSR reports (e.g., Cho, Michelon, and Patten, 2012a; 2012b).

\section{Conclusion}

In this article, we stress the importance of considering eye-tracking experiments to further investigate S\&E information from a user perspective. As Davenport and Beck (2001, 19; cited by Wedel and Pieters [2007, 126]) state, 'the eyes don't lie. If you want to know what people are paying attention to, follow what they are looking at'.

Using eye-tracking experiments enables the examination of visual attention related to CSR reports in a variety of mediums. Moreover, such eye-tracking technology allows for the investigation of how visual attention influences the reaction to information. Our illustrative experiment demonstrates that time spent viewing S\&E information included in CSR reports seems to matter to users in terms of shaping perceptions of a company's social responsibility. Moreover, users are more influenced by report texts rather other types of disclosure such as charts or images. This finding is somewhat reassuring but also surprising given the literature on graphs and how they are used to manage impressions (see, e.g., Cho, Michelon, and Patten 
2012a, 2012b) and other visuals from which one could conjecture that the power of such communication tools would lead to a larger influence on user perceptions of CSR. This finding on the importance of text (over visual disclosures) is in contrast to prior findings in the SEA literature (e.g., Cho et al., 2009) and demonstrates the types of findings, such as the time spent on specific information, that may only be available through eye-tracking experiments.

Our case used to illustrate eye-tracking experiments is subject to several limitations. First, participants in our experiment were mostly graduate students. While we believe these participants were appropriate subjects for this investigation in providing information on perceived preferences and key areas of attention focus, we concede that they may not be representative of all CSR report users, such as investment analysts. However, prior research suggests that student samples are appropriate as long as the task is matched to their familiarity level and abilities (e.g., McKnight, Choudhury, and Kacmar 2002). In this aspect, we believe that using a student sample was appropriate for this preliminary investigation. Second, students were recruited from a French-speaking university to evaluate an English-language (American) report. An English-language (American) report was used to provide a pre-validated, actual CSR report and the study recruitment announcement explicitly mentioned that a 'good understanding of written English' was required for participation, and participants were generally comfortable with written English. However, this potential language barrier and associated translation-related issue may have influenced participants' results (such as influencing the focus on the narrative of the report) and is a potential limitation of the study. Therefore, future research could use a French-speaking group to study a French-language report to ensure that results still hold.

Limitations aside, eye-tracking technology provides a fresh methodological perspective to SEA research. Given that experimental studies are fairly underutilised in the SEA realm (Parker 2005; Alewine 2010), eye-tracking technology presents a significant new path forward 
for research that studies visual attention. As shown by this paper, pinpointing where visual attention is spent may produce different conclusions than those seen in other studies, such as the importance of text that was seen in our illustrative experiment (versus the conclusions of Cho et al., 2009). Future research may consider comparing results from traditional experimental methodologies with those obtained with eye-tracking technology in order to provide further insights on the benefits of eye-tracking technology. For example, using a survey, Schmeltz (2012) finds that participants prefer CSR communication using a factual rather than an impressionistic writing style. Given the importance of narratives in the SEA field (Beattie 2014), it is necessary to use eye-tracking experiments to ensure that these results hold when visual attention is precisely and directly measured rather than when participants selfreport their levels of consideration/attention. Overall, this paper indicates that future SEA research could greatly benefit from using eye-tracking technology to continue to study visual attention. 


\section{Acknowledgements}

The authors wish to thank Matias Laine (handing Co-Editor), Carlos Larrinaga (Co-Editor and discussant at the 37th EAA Annual Congress), two anonymous reviewers, and the participants of the $2^{\text {nd }}$ French Congress on Social and Environmental Accounting Research in Montpellier, the 25th International Congress on Social and Environmental Accounting Research in Saint Andrews, the 2nd Critical Studies in Accounting and Finance Conference in Abu Dhabi, the 2014 AAA Public Interest Section Mid-Year Meeting in San Diego, the 37th European Accounting Association Annual Congress in Tallinn, research seminar at Bangor University and brown bag series at the ESSEC Research Center for Capitalism, Globalization and Governance $(\mathrm{C} 2 \mathrm{G} 2)$.

\section{Disclosure statement}

No potential conflict of interest was reported by the authors.

\section{Funding}

We also thank the HEC Paris GREHEC Laboratory (CNRS UMR 2959) for providing access to the Tobii eye-tracking machine and Charles Cho acknowledges the financial support provided by the ESSEC Research Centre (CERESSEC) and the Global Research Network program through the Ministry of Education of the Republic of Korea and the National Research Foundation of Korea [NRF-2016S1A2A2912421]. 


\section{References}

Alewine, H. C. 2010. "A Model for Conducting Experimental Environmental Accounting Research." Sustainability Accounting, Management and Policy Journal 1 (2): 256-291.

Alewine, H. C., and D. N. Stone. 2016. "The Joint Influence of Evaluation Mode and Benchmark Signal on Environmental Accounting-relevant Decisions." Social and Environmental Accountability Journal 36 (2): 124-152.

Atalay, A. S., H. O. Bodur, and D. Rasolofoarison. 2012. "Shining in the Center: Central Gaze Cascade Effect on Product Choice." Journal of Consumer Research 39 (4): 848-866.

Baldi, R., R. Di Pietra, P. Federighi, and A. Rufa. 2015. "Visualizing Financial Statements IFRS Compliant: Preliminary Experiments Adopting Eye Tracking Methodologies." Working paper. University of Siena.

Beattie, V. 2014. "Accounting Narratives and the Narrative Turn in Accounting Research: Issues, Theory, Methodology, Methods and a Research Framework." The British Accounting Review 46 (2): 111-134.

Beattie, V., and Jones, M. J. 2000a. "Changing Graph Use in Corporate Annual Reports: A Time-Series Analysis.” Contemporary Accounting Research 17 (2): 216-226.

Beattie, V., and Jones, M. J. 2000b. "Impression Management: The Case of Inter-country Financial Graphs.” International Accounting, Auditing \& Taxation 9 (2): 159-183.

Beattie, V., and Jones, M. J. 2002. "Measurement Distortion of Graphs in Corporate Reports: An Experimental Study." Accounting, Auditing \& Accountability Journal 15 (4): 546564.

Braun, M., C. Lee, G. Urban, and J. R. Hauser. 2009. "Does Matching Website Characteristics to Cognitive Styles Increase Online Sales?” Working paper. MIT Sloan School of Management.

Buswell, G. T. 1935. How People Look at Pictures: A Study of the Psychology of Perception of Art. Chicago: University of Chicago Press.

Chen, J., V. Arnold, and S. Sutton. 2010. "Does Web Disclosure of Environmental Information Affect Litigation Awards?” Working paper. University of Central Florida, Orlando, FL.

Chen, Y. S., J. Jermias, and T. Panggabean. 2016. "The Role of Visual Attention in the Managerial Judgment of Balanced-scorecard Performance Evaluation: Insights from using an Eye-tracking device." Journal of Accounting Research 54 (1): 113-146.

Cho, C. H., G. Michelon, and D. M. Patten. 2012a. "Impression Management in Sustainability Reports: An Empirical Investigation of the Use of Graphs." Accounting and the Public Interest 12 (1): 16-37.

Cho, C. H., G. Michelon, and D. M. Patten. 2012b. "Enhancement and Obfuscation through the Use of Graphs in Sustainability Reports: An International Comparison." Sustainability Accounting, Management and Policy Journal 3 (1): 74-88.

Cho, C. H., J. Phillips, A. Hageman, and D. M. Patten. 2009. "Media Richness, User Trust, and Perceptions of Corporate Social Responsibility: An Experimental Investigation of Visual Website Disclosure." Accounting, Auditing \& Accountability Journal 22 (6): 933-952.

Cohen, J. R., L. Holder-Webb, and V. L. Zamora. 2015. "Nonfinancial Information Preferences of Professional Investors." Behavioral Research in Accounting 27 (2): 127-153.

Danastas, L., and Gadenne, D. 2006. "Social and Environmental NGOs as Users of Corporate Social Disclosure." Journal of Environmental Assessment Policy and Management 8(1): 85-102.

Davenport, T. H., and J. C. Beck. 2001. The Attention Economy: Understanding the Currency of Business. Boston: Harvard Business School Press. 
Deegan, C. 2002. "The Legitimizing Effect of Social and Environmental Disclosures - A Theoretical Foundation." Accounting, Auditing \& Accountability Journal 15 (3): 282-311.

Dilla, W. N., D. J. Janvrin, J. D. Perkins, and R. Raschke. 2014. "Assurance on Environmental Performance and Investor Judgments: The Impact of Environmental Attitudes." Working paper. Iowa State University.

Duchowski, A. T. 2002. "A Breadth-first Survey of Eye-tracking Applications." Behavior Research Methods, Instruments, \& Computers 34 (4): 455-470.

Elijido-Ten, E. 2011. "Media Coverage and Voluntary Environmental Disclosures: a Developing Country Exploratory Experiment." Accounting Forum 35 (3): 139-157.

Federighi, P., A. Federico, and A. Rufa. 2013. "On the Development of a Data Base for Saccadic Parameters and Main Sequence Relationships - A Quantitative Study of a Video-based Eye-tracking." Romanian Journal of Biophysics 3 (3): 125-137.

Glöckner, A., and A.-K. Herbold. 2008. "Information Processing in Decisions under Risk: Evidence for Compensatory Strategies based on Automatic Processes.” Max Planck Institute Collective Goods Preprint, No. 2008/42.

Hervet. G., K. Guérard, S. Tremblay, and M. S. Chtourou. 2011. "Is Banner Blindness Genuine? Eye Tracking Internet text advertising." Applied Cognitive Psychology 25 (5): 708-716.

Hoffman, J. E., and B. Subramaniam. 1995. "The Role of Visual Attention in Saccadic Eye Movements." Perception \& Psychophysics 57 (6): 787-795.

Huang, X. B., and L. Watson. 2015. "Corporate Social Responsibility Research in Accounting." Journal of Accounting Literature, 34: 1-16.

Jang, Y.-M., S. Lee, R. Mallipeddi, H.-W. Kwak, and M. Lee. 2011. “Recognition of Human's Implicit Intention Based on an Eyeball Movement Pattern Analysis." Neural Information Processing 7062: 138-145.

Kang, Z. K., S. Mandal, J. Crutchfield, A. Millan, and S. McClung. 2016. "Designs and Algorithms to Map Eye Tracking Data with Dynamic Multi-element Moving Objects." Computational Intelligence and Neuroscience. Article ID 9354760.

Kaplan, S. E., and P. S. Wisner. 2009. "The Judgmental Effects of Management Communications and a Fifth Balanced Scorecard Category on Performance Evaluation." Behavioral Research in Accounting 21 (2): 37-56.

Kennedy, J., T. Mitchell, and S. E. Sefcik. 1998. "Disclosure of Contingent Environmental Liabilities: Some Unintended Consequences?” Journal of Accounting Research 36 (2): 257-277.

Kerlinger, F. N., and H. B. Lee. 2000. Foundations of Behavioral Research, $4^{\text {th }}$ Edition. Wadsworth, Thomson Learning.

Matsumura, E. A., R. Prakash, and S. C. Vera-Muñoz. 2014. "Firm-Value Effects of Carbon Emissions and Carbon Disclosures." The Accounting Review 89 (2): 695-724.

Mawad, F., M. Trías, A. Giménez, A. Maiche, and G. Ares. 2015. "Influence of Cognitive Style on Information Processing and Selection of Yogurt Labels: Insights from an Eyetracking Study." Food Research International 74: 1-9.

McEwen, R. A., and J. E. Hunton. 1999. "Is Analyst Forecast Accuracy Associated with Accounting Information Use?" Accounting Horizons 13 (1): 1-16.

McKnight, D. H., L. L. Cummings, and N. L. Chervany. 1998. "Initial Trust Formation in New Organizational Relationships." Academy of Management Review 23 (3): 473-90.

McKnight, D. H., V. Choudhury, and C. Kacmar. 2002. "Developing and Validating Trust Measures for E-commerce: An Integrative Typology." Information Systems Research 13 (3): 334-359. 
Merkl-Davies, D. M., and N. M. Brennan. 2007. "Discretionary Disclosure Strategies in Corporate Narratives: Incremental Information or Impression Management?” Journal of Accounting Literature 27: 116-196.

Merkl-Davies, D. M., and N. M. Brennan. 2011. "A Conceptual Framework of Impression Management: New Insights from Psychology, Sociology and Critical Perspectives." Accounting and Business Research 41 (5): 415-437.

Messick, S. 1976. "Personality Consistencies in Cognition and Creativity." In S. Messick \& Associates (Eds.), Individuality in learning (pp. 4-22). San Francisco: Jossey-Bass.

Milne, M. J., and D. M. Patten. 2002. "Securing Organizational Legitimacy: An Experimental Decision Case Examining the Impact of Environmental Disclosures." Accounting, Auditing \& Accountability Journal 15 (3): 372-405.

Morsing, M, and Beckmann, S. C. 2006. Strategic CSR Communication. DJØF Publishing.

Murray, A., D. Sinclair, D. Power, and R. Gray. 2006. "Do Financial Markets Care about Social and Environmental Disclosure?: Further Evidence and Exploration from the UK." Accounting, Auditing \& Accountability Journal, 19 (2): 228-255.

Nisiforou. E. A., E. Michailidou, and A. Laghos. 2014. "Using Eye Tracking to Understand the Impact of Cognitive Abilities on Search Tasks", Universal Access in Human-Computer Interaction. Design for All and Accessibility Practice Volume 8516 of the series Lecture Notes in Computer Science: 46-57.

Nixon, H. K. 1924. "Attention and Interest in Advertising." Archives of Psychology 72: 5-67.

Oliver, S. 2000. "Message from the CEO: A Three-minute Rule?" Corporate Communications: An International Journal 5 (3): 158-167.

Parker, L. D. 2005. "Social and Environmental Accountability Research: A View from the Commentary Box." Accounting, Auditing \& Accountability Journal 18 (6): 842-860.

Pérez, A. 2015. "Corporate reputation and CSR reporting to stakeholders: Gaps in the literature and future lines of research." Corporate Communications: An International Journal 20(1): 11-29.

Rayner, K. 1978 "Eye Movements in Reading and Information Processing." Psychology Bulletin 5 (3): 618-660.

Rayner, K. 1998. "Eye Movements in Reading and Information Processing: 20 Years of Research." Psychology Bulletin 124 (3): 372-422.

Reimsbach, D., and R. Hahn. 2015. "The Effects of Negative Incidents in Sustainability Reporting on Investors' Judgments-an Experimental Study of Third-party Versus Self-disclosure in the Realm of Sustainable Development." Business Strategy and the Environment, 24 (4): 217-235.

Robinson, D. A. 1963. "A Method of Measuring Eye Movement Using a Scleral Search Coil in a Magnetic Field", IEEE Transactions on Bio-medical Electronics 10 (4): 137-145.

Schmeltz, L. 2012. "Consumer-oriented CSR Communication: Focusing on Ability or Morality?" Corporate Communications: An International Journal 17(1): 29-49.

Shi, S. W., M. Wedel, and R. Pieters. 2013. "Information Acquisition during Online Decision Making: A Model-based Exploration using Eye-tracking Data." Management Science 59 (5): 1009-1026.

Steenkamp, N., and J. Hooks. 2011. "Does Including Pictorial Disclosure of Intellectual Capital Resources Make a Difference?" Pacific Accounting Review 23 (1): 52-68.

Tsianos, N., P. Germanakos, Z. Lekkas, C. Mourlas, and G. Samaras. 2009. "Eye-tracking Users' Behavior in Relation to Cognitive Style within an E-learning Environment." 2009 Ninth IEEE International Conference on Advanced Learning Technologies.

Wedel, M., and R. Pieters. 2007. "A Review of Eye-tracking Research in Marketing." Review of Marketing Research 4: 123-147. 
Wedel, M., and R. Pieters. 2014. "Looking at vision." In The Routledge Companion to the Future of Marketing, edited by L. Moutinho, E. Bigné, and A. K. Manrai, 177-189. Abingdon: Routledge.

Wong, R., and Millington, A. 2014. "Corporate Social Disclosures: A User Perspective on Assurance." Accounting, Auditing \& Accountability Journal 27(5): 863-887.

Wynder, M., K.-U. Wellner, and K. Reinhardt. 2013. "Rhetoric or Reality? Do Accounting Education and Experience Increase Weighting on Environmental Performance in a Balanced Scorecard?" Accounting Education 22 (4): 366-381.

Zahller, K. A., V. Arnold, and R. W. Roberts. 2015. "Using CSR Disclosure Quality to Develop Social Resilience to Exogenous Shocks: A test of Investor Perceptions.” Behavioral Research in Accounting 27 (2): 155-177.

Zhilong, T., W. Rui, and Y. Wen. 2011. "Consumer Responses to Corporate Social Responsibility (CSR) in China.” Journal of Business Ethics 101 (2): 197-212. 


\section{Appendices}

\section{Appendix 1. Previous Research on Eye-Tracking Experiments}

\begin{tabular}{|c|c|}
\hline Nixon (1924) & $\begin{array}{l}\text { Known as one of the original researchers who used eye-tracking set-ups } \\
\text { within the marketing field. Since then, many other researchers have } \\
\text { followed in his footsteps. }\end{array}$ \\
\hline Buswell (1935) & $\begin{array}{l}\text { Eye-trackers measure two key components of eye movements when an } \\
\text { individual scans a visual scene - saccades and fixations. }\end{array}$ \\
\hline Rayner (1978) & $\begin{array}{l}\text { Eye-movement data 'clearly provide the hope of telling us something } \\
\text { important about the processing activities involved in a particular task.' }\end{array}$ \\
\hline $\begin{array}{l}\text { Hoffman and } \\
\text { Subramaniam (1995) }\end{array}$ & Attention is reflected in eye movements. \\
\hline Rayner (1998) & $\begin{array}{l}\text { Saccades are quick }{ }^{20} \text { eye movements made constantly, and fixations are } \\
\text { made between the saccades, when the eye is still and shortly stops on an } \\
\text { area of interest. }{ }^{21}\end{array}$ \\
\hline $\begin{array}{l}\text { Wedel and Pieters } \\
(2007 ; 2014)\end{array}$ & $\begin{array}{l}\text { To obtain time and scanpath (pattern of fixations and saccades an eye- } \\
\text { tracker device records) data, the most commonly-used method is the } \\
\text { infrared corneal reflection method, when a light source emits infrared } \\
\text { light, and a video-camera measures both the distance and the angle of the } \\
\text { reflection of the infrared light from the center of the pupil. }\end{array}$ \\
\hline Oliver (2000) & $\begin{array}{l}\text { Analyses of eye-movement data to show that employees spend similar } \\
\text { amounts of time reading their CEO messages regardless of time available, } \\
\text { content, design, status or corporate culture. }\end{array}$ \\
\hline Jang et al. (2011) & $\begin{array}{l}\text { New approach for a human's recognition system based on an eyeball } \\
\text { movement pattern analysis by presenting a comprehensive classification } \\
\text { of human implicit intention, which they define as informational and } \\
\text { navigational intent. }\end{array}$ \\
\hline al. (2011) & $\begin{array}{l}\text { Investigation of whether Internet users avoid looking at advertisements } \\
\text { inserted on a non-search website using an analysis of eye movements, and } \\
\text { whether the advertisement content is kept in memory. }\end{array}$ \\
\hline $\begin{array}{l}\text { Shi, Wedel, and Pieters } \\
\text { (2013) }\end{array}$ & $\begin{array}{l}\text { Horizontal and contiguous eye movements play an important role in } \\
\text { information acquisition, and that gaze cascades play an important role in } \\
\text { decisions. }\end{array}$ \\
\hline Baldi et al. (2015) & $\begin{array}{l}\text { Investigation of how the way accounting information is disclosed } \\
\text { influences visual attention and, in turn, the decision-making process } \rightarrow \\
\text { participants pay more visual attention to information disclosed using IFRS } \\
\text { rules compared to information disclosed using Italian standards. }\end{array}$ \\
\hline $\begin{array}{l}\text { Chen, Jermais, and } \\
\text { Panggabean (2016) }\end{array}$ & $\begin{array}{l}\text { Examination of the managerial judgment process during balanced- } \\
\text { scorecard performance evaluations } \rightarrow \text { when aware of their existence, } \\
\text { managers focus on strategically linked performance measures and that the } \\
\text { presentation format of the strategy information does not significantly } \\
\text { affect attention focus. In addition, the more time managers spend focusing } \\
\text { on strategically linked performance measures, the more consistent their } \\
\text { decisions are with the achievement of the strategic objectives of their } \\
\text { business unit. }\end{array}$ \\
\hline
\end{tabular}

\footnotetext{
${ }^{20}$ It is one of the fastest movement a human body can achieve - up to 1,000 eye movements/second (Wedel and Pieters, 2014).

${ }^{21}$ For a more detailed description of the eye functioning, see Wedel and Pieters (2007) for example.
} 


\section{Appendix 2. Experimental Questionnaire}

In answering the following questions, you will respond to a rating scale with seven spaces; please check on the space that best describes your opinions.

1. This company is truthful in its dealings with me.

DISAGREE strongly somewhat slightly neither slightly somewhat strongly AGREE

2. I would characterize this company as honest.

DISAGREE strongly somewhat slightly neither slightly somewhat strongly AGREE

3. This company would keep its commitments.

DISAGREE strongly somewhat slightly neither slightly somewhat strongly AGREE

4. This company is sincere and genuine.

DISAGREE strongly somewhat slightly neither slightly somewhat strongly

AGREE

5. I would feel comfortable depending on the information provided by this company.

DISAGREE strongly somewhat slightly neither $\overline{\text { slightly somewhat strongly }}$ AGREE

6. I can always rely on this the information provided in this company's report.

DISAGREE strongly somewhat slightly neither slightly somewhat strongly AGREE

7. I feel that I could count on the information provided in this company's report.

DISAGREE strongly somewhat slightly neither slightly somewhat strongly AGREE

8. If I were evaluating the social and environmental performance of this company, I would trust the information provided in this company's report.

DISAGREE strongly somewhat slightly neither slightly somewhat strongly 
9. If I were evaluating this company as a potential investment, I would trust the information provided in this company's report.

DISAGREE

$\begin{array}{rccccc} & : & : & : & & \\ \text { strongly } & \text { somewhat } & \text { slightly } & \text { neither } & \text { slightly } & \text { somewhat strongly }\end{array}$

10. Relative to other companies in its industry, this company appears to be:

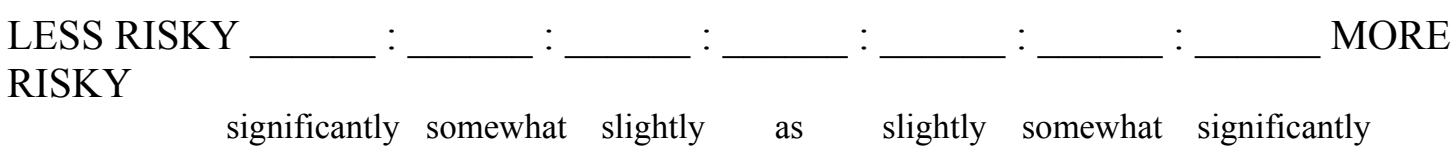

11. How socially and environmentally responsible is this company?

NOT AT ALL RESPONSIBLE EXTREMELY RESPONSIBLE

12. Visually, this report resembled other reports I think highly of.

DISAGREE strongly somewhat slightly neither slightly somewhat strongly AGREE

13. This report was simple to navigate.

DISAGREE strongly somewhat slightly neither slightly somewhat strongly AGREE

14. Within this report, it was easy to find the information I wanted.

DISAGREE strongly somewhat slightly $\overline{\text { neither }} \overline{\text { slightly somewhat strongly }}$ AGREE

15. The name of the company in the report was:

_ McKnight's Company

Alon, Inc.

_ CTA Enterprises

- None of the Above

16. Did you encounter any technical difficulties during the study? (Open response)

17. My gender is:

Male

Female 
18. My present age is:

Less than 20

$41-50$

$20-25$

$51-60$

26-30

Over 60

$31-40$

19. The highest level of education that I have completed is:

Less than high school

High school

Some college

Bachelor's Degree

Master's Degree

Other Advanced Degree

20. I care about the social and environmental performance of companies.

DISAGREE strongly somewhat slightly neither $\overline{\text { slightly somewhat strongly }}$

AGREE

21. I consider a company's social and environmental performance when making product choice decisions.

DISAGREE strongly somewhat slightly neither $\overline{\text { slightly somewhat strongly }}$ AGREE

22. I consider a company's social and environmental performance when I make investment decisions.

DISAGREE strongly somewhat slightly neither slightly somewhat strongly AGREE

23. I read a company's corporate social responsibility (CSR) report before making an investment decision.

DISAGREE strongly somewhat slightly neither slightly somewhat strongly AGREE

24. I read a company's corporate social responsibility (CSR) report before making a product choice decision.

DISAGREE strongly somewhat slightly neither slightly somewhat strongly 
Table 1. Sample Demographics

\begin{tabular}{lc}
\hline Demographic Features & Sample Percentage \\
\hline \hline Age & \\
\hline 25 years or younger & $72 \%$ \\
$26-30$ years & $13 \%$ \\
Over 30 years & $15 \%$ \\
\hline Education Level & \\
\hline Non-college graduate & $15 \%$ \\
Bachelor's degree & $28 \%$ \\
Graduate degree & $57 \%$ \\
\hline Gender & \\
\hline Female & $66 \%$ \\
Male & $34 \%$ \\
\hline $\mathrm{N}=102$ & \\
\hline
\end{tabular}


Table 2. Participant Attitudes

Mean

(1-7 scale)

Care about social and environmental (S\&E) performance

5.67

Consider S\&E performance with product choice

4.50

Consider S\&E performance with investments

4.74

Read CSR with product choice

2.63

Familiarity with CSR reports

3.89

Percentage who knew what a CSR report was prior to the study

$70 \%$ 
Table 3. Regression Standardized Coefficients

\begin{tabular}{llll}
\hline Independent Variable & $\begin{array}{l}\text { S\&E } \\
\text { Responsibility }\end{array}$ & Trusting Beliefs & Trusting Intentions \\
\hline \hline Panel A. Effect of total time & & & \\
Total time & $\mathbf{0 . 1 9 8 * *}$ & 0.136 & 0.900 \\
Adjusted R & .030 & .009 & -.002 \\
F Statistic & $\mathbf{4 . 0 7 9 * *}$ & 1.890 & .811 \\
Panel B. Effect of time by medium & & & \\
Text duration & $\mathbf{. 2 8 7 * *}$ & .137 & $\mathbf{. 1 9 6 *}$ \\
Chart duration & -.089 & .116 & $\mathbf{- . 2 0 3 *}$ \\
Image duration & -.016 & -.001 & .004 \\
Adjusted R & .034 & .009 & .011 \\
F Statistic & $\mathbf{2 . 1 9 4 *}$ & 1.890 & 1.360 \\
\hline
\end{tabular}

$* \mathrm{p}<.10$, two-tailed.

$* * \mathrm{p}<.05$, two-tailed.

$* * * \mathrm{p}<.01$, two-tailed. 
Figure 1. Two Steps to Assess the Reaction to SEA Information

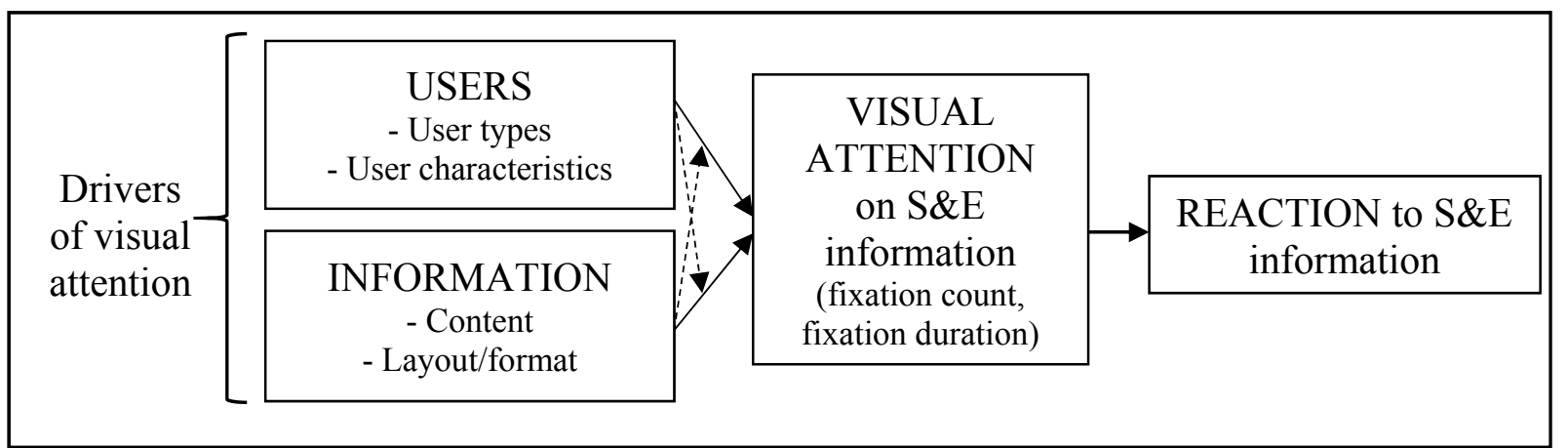


Figure 2. Example of Eye Gaze Plot

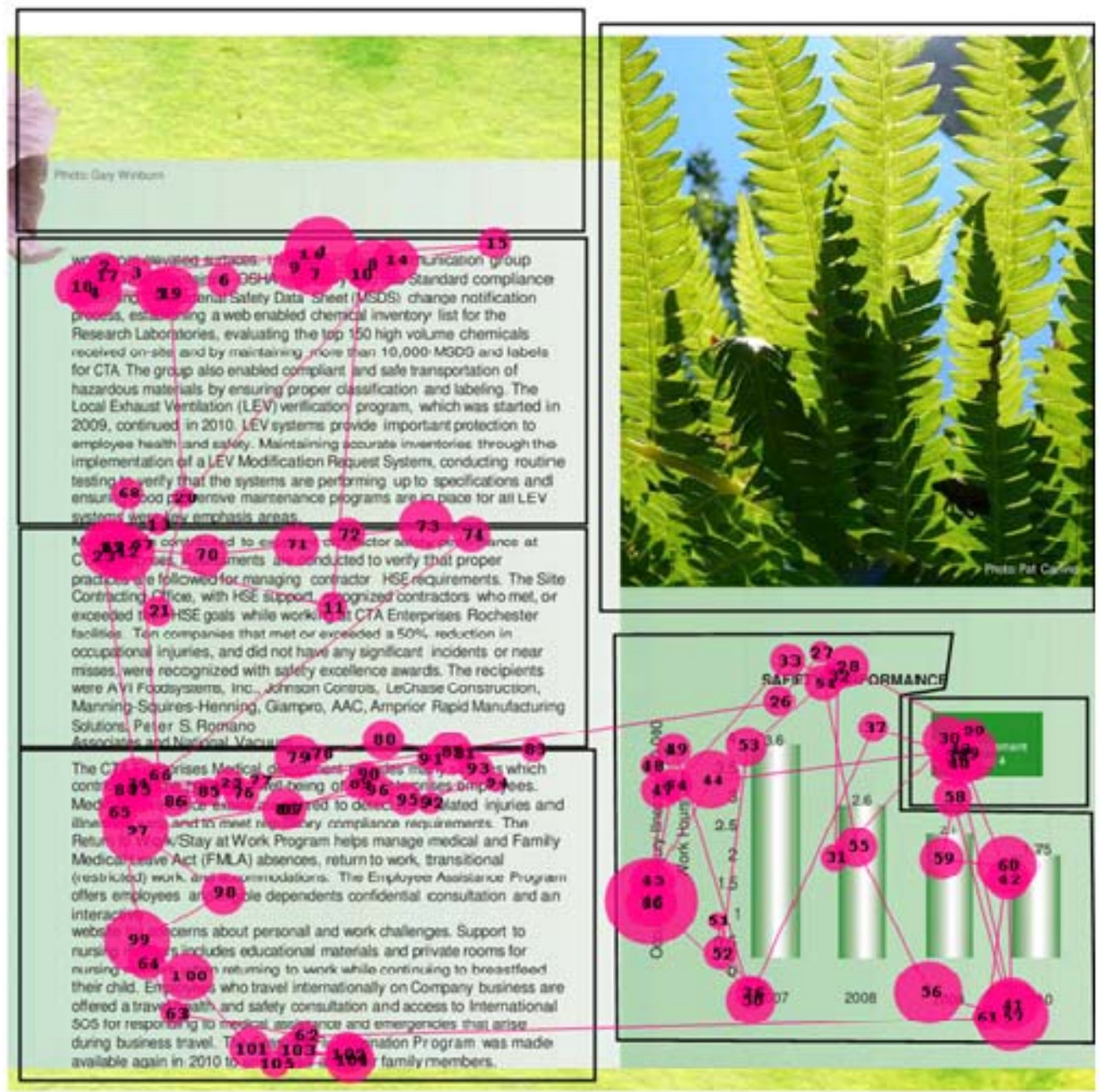

CTAENTERPRISES 5 